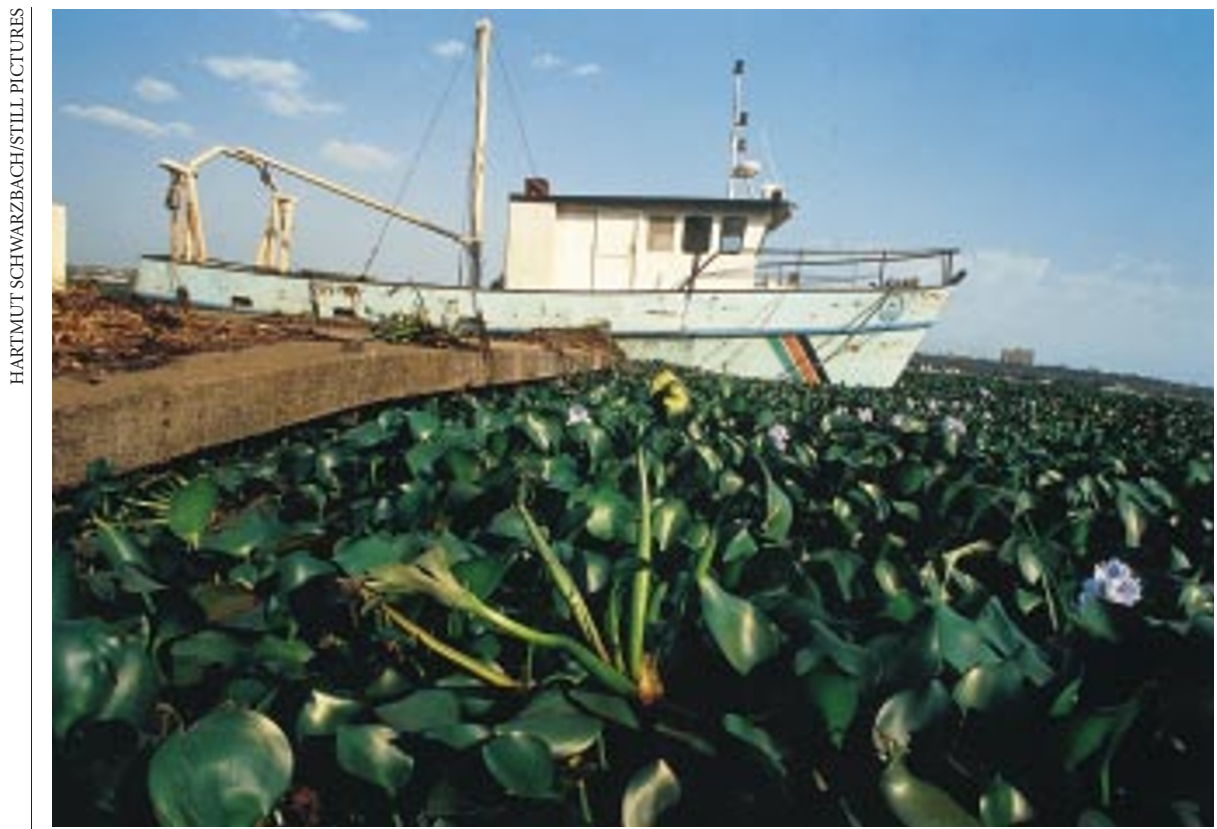

Plant-locked: the spread of the water hyacinth in Lake Victoria has closed small ports and harbours.

tions. Cases of accidental introductions are growing because of increased shipping and the use of ballast water. Ballast water, acquired in one port and dumped in another, brings large numbers of live animals to new habitats. Around 1982, a small comb jellyfish was brought in this way from the east coast of the Americas to the Black Sea. This organism became well established and devastated the fisheries, affecting two million people. In a poor exchange, the zebra mussel was apparently taken in ballast water from the Caspian Sea to the Great Lakes of North America around 1986. This mussel is doing so well in its new habitat and its numbers are now so high that it controls the ecological dynamics of many areas, and adversely affects waterworks such that remediation is costing billions of dollars.

Doing something about invasive species will not be easy, as Bright points out, because we generally do not know which organisms will become successful invaders, where and when invasions will occur, or what effects they will have. If ever there was a rationale for the precautionary principle on the release of any biotic material into a new ecosystem, this is it. The policy response to the threat of invasions has been weak and uncoordinated, and only the most devastating invaders get serious attention. Bright thinks we need to strengthen the treaties relevant to invasive species, develop codes of conduct for industries involved in the trade of biotic material, create an information clearing-house, improve our capabilities of biological control, and increase ecological literacy. All of these are important and achievable goals.

There is some hope of providing an international focus on the problem, and for the development of tools and determination officinarum), ginseng (Panax ginseng), garlic (Allium sativum), urd bean (Vigna mungo) and broad (or fava) bean (Vicia faba).

His work is library-based in the tradition of James Frazer's The Golden Bough; little, if, any fieldwork appears to have been undertaken. Of the book's 568 pages, 230 are devoted to notes and bibliography. On the positive side he writes in a clear, jargon-free style. On the negative side, like Frazer, he accumulates so much information that the reader is overwhelmed. In the earlier chapters Simoons himself seems overwhelmed, to the extent that he is reluctant to draw conclusions from his assembled evidence. Perhaps conclusions are there, but they are hard to find.

Simoons is right to challenge the currently prevalent view that mankind's relationship with plants is derived from a plant's economic, nutritive or medicinal value, or its ability to harm. For example, some people did develop favism after consuming broad beans, but this alone was not responsible for the Pythagorean ban on beans: there were more complex cultural reasons. However, his case could have been presented in a more succinct and convincing manner.

A more disciplined approach, which limited the amount of information and gave greater prominence to his hypothesis, would have improved the work and made it more useful. As it is, only the most determined and alert readers will successfully negotiate their way through the often repetitive evidence to reach the valid, but frequently somewhat unrelated, findings.

Roy Vickery is in the Department of Botany, The Natural History Museum, London SW7 5BD, UK.

Harold A. Mooney is in the Department of

Biological Sciences, Stanford University, Stanford, California 94305, USA.

\section{Ritual meanings lost in a vegetable stew}

\section{Plants of Life, Plants of Death}

by Frederick J. Simoons

University of Wisconsin Press: 1999. 568 pp.

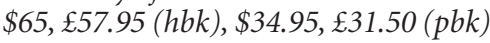

\section{Roy Vic kery}

Mankind's attitude to the ritual use of plants arose primarily from basic human concerns about life, fertility and death, rather than medicinal or nutritional factors - according to Frederick Simoons, at least.

Simoons, of the University of California, seeks to demonstrate this by accumulating a vast amount of information on holy basil (Ocimum sanctum), sacred figs (Ficus religiosa and $F$. indica), mandrake (Mandragora

Æ̊ 1999 Macmillan Magazines Ltd
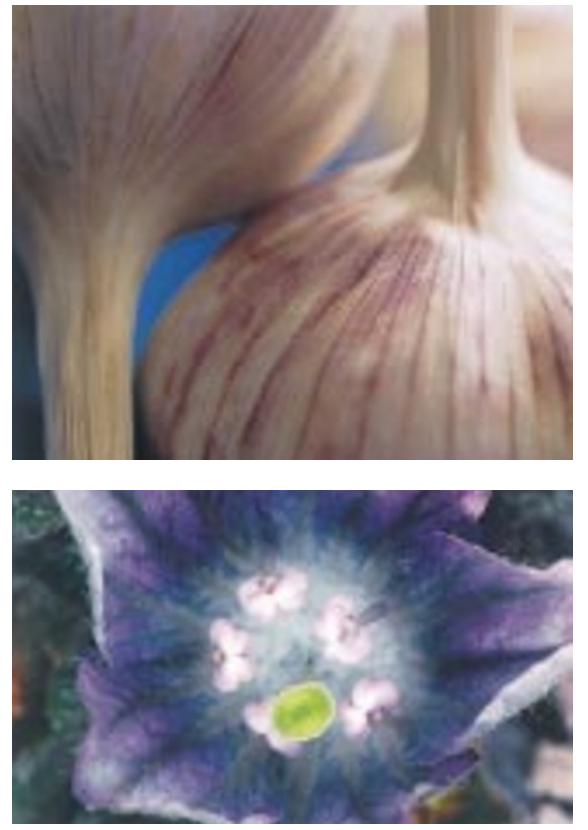

Cultivated by culture: garlic (top) and mandrake became popular for their ritualistic use. 